\title{
Consumer attitudes towards the use of autonomous vehicles: Evidence from United Kingdom taxi services
}

\author{
Omar Hasan $^{\text {a }}$, Julie McColl ${ }^{\mathrm{a}}$, Tom Pfefferkorn ${ }^{\mathrm{a}}$, Samer Hamadneh ${ }^{\mathrm{b}}$, Muhammad Alshurideh ${ }^{\mathrm{b}, \mathbf{c}^{*}}$ and \\ Barween Al Kurdi ${ }^{d}$
}

${ }^{a}$ Heriot-Watt University, United Kingdom

${ }^{b}$ Department of Marketing, School of Business, The University of Jordan. Amman, Jordan

${ }^{c}$ Department of Management, College of Business Administration, University of Sharjah, United Arab Emirates

${ }^{d}$ Department of Business Administration, Faculty of Economics and Administrative Sciences, The Hashemite University, Zarqa, Jordan

\section{CH R O N I C L A B T R A C T}

Article history:

Received: June 22, 2021

Received in revised format: September 21, 2021

Accepted: November 20, 2021

Available online: November 22, 2021

Keywords:

Autonomous vehicle

Consumers attitudes

Theory of planned behavior

Ride-hailing services

United Kingdom

\begin{abstract}
The primary aim of this research is to determine attitudes held towards autonomous vehicles (AVs) and understand their impact on intentions to use the service among ride-hailing users in the UK. Based on the Theory of Planned Behaviour model, an online, self-administered survey was used to collect data from 151 consumers (18-24-year-olds). The relationship between variables was measured using a Spearman's Rank test in SPSS. The results of this study found all categories (overall attitude, perceived ease-of-use, perceived value, perceived safety, perceived risk, technology, environmentalism, subjective norms, perceived behavioural control) received a positive mean score. From these results, it can be concluded that this sample holds positive attitudes towards AVs and intend to use the service when they are made available. A positive score for perceived risk, however, indicated that this group thought there may be safety concerns when using this technology. The main contribution of this study is providing data to a new, and rapidly evolving field of research and thus the findings of the present study contribute to ongoing research related to consumers attitudes of AVs. Managerially, companies that focus on developing and implementing AV taxis need to focus more on the safety benefits of such vehicles.
\end{abstract}

\section{Introduction}

An autonomous vehicle (AV) uses sensors and algorithms to scan the environment, and can drive independently, without human control or supervision (McBride, 2016; Surden \& Williams, 2016). It has been reported that such innovation will lead to many benefits including a reduction in road fatalities, a fall in transport costs and, lower levels of congestion (Araujo et al., 2012; Rathore, 2016; Almaazmi et al., 2020; Alameeri et al., 2021; Nuseir et al., 2021; Obeidat et al., 2021). Firms such as Tesla, Uber, Mercedes Benz, and Google, are currently investing heavily in the development of these vehicles (Davidson and Spinoulas, 2015; Ahmad et al., 2021). Due to the prohibitively high initial retail price, it has been suggested that AVs will first be made available through ride-hailing taxi services (Freedman et al., 2018). However, there are concerns over the safety of these vehicles and it is unclear if this may lead to consumers holding negative opinions (Shariff et al, 2017). Hence, it becomes increasingly important to understand consumers' attitudes towards this technology, to assess whether individuals are likely to adopt this service (Argyriou \& Melewar, 2011; Tussyadiah et al., 2017; Alshurideh et al., 2019; Al Kurdi et al., 2020; Abuhashesh et al., 2021; Alshurideh et al., 2021). The need for more research on this is, therefore, urgent as Waymo has

* Corresponding author.

E-mail address: malshurideh@sharjah.ac.ae (M. Alshurideh)

(C) 2022 by the authors; licensee Growing Science, Canada. doi: $10.5267 /$ j.ijdns.2021.11.010 
already launched an autonomous taxi service in Phoenix, Arizona (McGee, 2021). Other firms such as Baidu, Aurora, Zoox and Uber are closing behind, with testing set to resume on roads shortly (Templeton, 2020). The companies leading this transition are predominantly focused on North America and, as a result, much of the current literature is concerned with this region. Despite this, Oxbotica recently began testing their vehicles in Oxford, with trials in London confirmed (BBC, 2020). The British Government has also indicated their support for this innovation, estimating this market to be worth $£ 41.7$ billion by 2035 , and creating 40,000 jobs (Gov.uk, 2021). This suggests that the UK ride-hailing industry is an appropriate context for this study.

In the meantime, due to the more frequent testing, and increasing public awareness of these vehicles, attitudes are evolving as people become more familiar with the technology (Liljamo et al., 2018). Extant research calls for further studies to examine consumer attitudes toward AVs (Pettigrew et al., 2018; Panagiotopoulos \& Dimitrakopoulos, 2018). Therefore, the aim of this research is to determine attitudes held towards AVs and understand their impact on the intention to use the service. To achieve this, the set of objectives are as follows:

- $\quad$ To determine the attitudes which are held towards autonomous vehicles.

- To understand the salient beliefs, subjective norms, and behavioural control components, and how they influence attitudes.

- To evaluate the relationship between attitudes, subjective norms, perceived behavioural control and intentions to use the service.

Through this research, a better understanding of consumers' attitudes towards using AVs can be gained. This paper is structured as follows: the next section reviews the current literature in attitudinal theory, to determine a theoretical framework to measure attitudes towards autonomous vehicles (AVs), in the context of the ride-hailing UK taxi industry. The third section describes methodology used to test research hypotheses. Then, the fourth section presents data analysis and discusses the study findings. The last section concludes the study and makes some recommendations for marketers and future researchers.

\section{Literature background}

\subsection{Attitudinal theory}

While there is no one universally accepted definition of attitudes in the current literature, studies have concluded that attitudes are a tendency or disposition (Bogardus, 1931; Droba, 1933), associated with or targeted at an object (Lundberg, 1929; Krueger \& Reckless, 1931; Greenwald, 1989), which produces an evaluation (Triandis, 1991; Olson \& Zanna, 1993; Albarracin et al., 2005; Fazio, 2007). Rosenberg and Hovland (1960) proposed a three-component model to structure the attitudes construct, arguing that attitudes consist of three parts; cognition, affect and behaviour. Cognitions are based on thoughts and beliefs held towards an object; that is a rational route as evaluations are predicated on knowledge, information, and structure (Breckler, 1984; Crano \& Prislin, 2011). The affective component refers to the emotional reaction evoked by an attitude object; this consists of moods and feelings brought on by experiencing said object (Fiske et al., 2010; Petty, and Krosnick, 2014; Obeidat et al., 2019; Alsharari \& Alshurideh, 2020). Emotions such as fear, disgust, admiration are all indicative of this component which is considered by many researchers to be the most significant (Day, 1972; Ajzen, 1989; Alshurideh et al., 2012; AlDhuhouri et al., 2020). The behavioural aspect is concerned with an individual's actions and intentions towards the object; an attitude is grounded in reflection on past behaviour towards the object (Fazio, 1987; Fiske, et al., 2010; Kurdi \& Alshurideh, 2020; Alshurideh et al., 2020). This component also identifies situations where an individual may encounter an attitude object without a prior cognitive or affective response and thus, behaviour alone is the basis for an attitude (Crano \& Prislin, 2011; Al-Dmour et al., 2014; Kurdi et al., 2020a). The next section discusses the relationship between attitudes and behaviour.

\subsection{Attitudes and behaviour}

Much of the available literature on consumer attitudes is concerned with the degree of which attitudes can predict behaviour (e.g., Zanna \&Fazio, 1982; Fazio, 1986; Alshurideh et al., 2019; Kurdi et al., 2021). Thus, understanding the relationship between the two variables has become the primary motivation for many researchers; aiming to influence, and change, behaviour through the modification of an individual's attitude (Semin \& Fiedler, 1996; Al Kurdi et al., 2020b). The current work demonstrates strong evidence in the literature showing a positive correlation between attitudes and behavior (Goodmonson \& Glaudin, 1971; Seligman et al, 1979; Theodorakis, 1994; Lawton et al., 2009). The theory of Reasoned Action (Ajzen \& Fishbein, 1980) and theory of Planned Behaviour (Ajzen, 1985) have been widely utilised to understand the relationship between attitudes and behaviour (Ajzen, 2001; Crano and Prislin, 2011). In particular, the theory of reasoned action has been used to predict how individuals will behave based on their pre-existing attitudes and behavioural intentions. Subjective norms are also considered in the theory which are concerned with the perceived level of social expectation, or pressure, towards a given behaviour and the respective motivation to comply (Fazio, 1990; Semin \& Fiedler, 1996; Alsuwaidi et al., 2020). Once 
an attitude has been formed and subjective norms considered, the model suggests an individual will then develop intentions towards a behaviour before finally engaging in that behaviour (Fazio, 1990; Fiske et al., 2010; Fishbein \& Ajzen, 2011).

The theory of Planned Behaviour (1985) extended this framework to include perceived behavioural control; the extent to which an individual believes they can perform the behaviour (Semin and Fiedler, 1996; Crano \& Prislin, 2006; Ajzen, 2008; Akour et al., 2021). If attitudes and subjective norms are favourable, combined with perceived behavioural control, the model dictates an individual will act upon their intention (Ajzen, 1991; Ajzen, 2008; Crano \& Prislin, 2011).

The two theories have been used extensively in the literature with positive results, particularly in a marketing context, relating to unfamiliar goods (Arvola et al, 1999), coupon usage (Shimp and Kavas, 1984), halal products (Lada, Tanakinjal \& Amin, 2009), and therefore suggesting the that these theories are strong predictors of behaviour (Ajzen, 2008). The next section reviews the current literature on attitudes towards ride-hailing.

\subsection{Attitudes toward autonomous driving and hypothesis development}

Autonomous vehicles (AVs) are cars that can drive without human intervention; the car uses algorithms, cameras, and software to navigate the environment and make driving-related decisions (McBride, 2016; Surden and Williams, 2016). It has been suggested that applying this technology in the taxi industry is appropriate due to economic reasons as the initial cost of ownership will not be financially viable for most individuals (Daily \& Medasani, 2017; Freedman et al., 2018). As a result, consumers who use ride-hailing apps are thought to be the first who will have access to this technology (Tussyadiah et al., 2017).

Currently the literature does not suggest there is complete consensus in consumer attitudes. Nevertheless, the majority of research shows support (Payre et al., 2014; Tussyadiah et al., 2017; Hulse et al., 2018; Liljamo et al., 2018; Hilgarter \& Granig, 2020), whilst there is some significant concern (Haboucha et al., 2017; Wang et al, 2020) over AVs. Therefore, the following hypothesis will be tested:

\section{H1: Attitudes towards AVs are positive.}

Further, current research (Kyriakidis et al., 2015; Haboucha et al., 2017; König \& Neumayr, 2017; Wang et al, 2020) agrees that the early adopters of this technology will be young people; and gender also appears to play a significant role in the formation of attitudes towards autonomous vehicles, with research (Payre et al., 2014; Charness et al, 2018; Hulse et al., 2018; Liljamo et al., 2018; Chen, 2019; Hudson et al., 2019), suggesting men have more favourable attitudes than females, who cite concerns over safety and the fear of losing control (Howard \& Dai, 2014; Pettigrew et al, 2019). As such, this statement will be explored:

\section{$\mathbf{H}_{2}$ : Male respondents have more favourable attitudes towards AVs.}

A study by Panagiotopoulos and Dimitrakopoulos (2018), found that ease-of-use, perceived usefulness, and trust were the most significant factors in determining attitudes towards AVs. This has been supported by additional studies (Choi and Ji, 2015; Chen, 2019; Lee et al, 2019; Liu et al., 2019; Acheampong and Cugurullo, 2019), confirming the importance of these factors. Building on the idea of value, perceived enjoyment is commonly mentioned (Haboucha, Ishaq \& Shiftan, 2017; Chen, 2019); some studies (Schoettle \& Sivak, 2014; Kyriakidis et al., 2015; Pakusch et al, 2020), specify the willingness to pay more for the service. In line with these claims, the following hypotheses will be used:

$\mathbf{H}_{3}$ : Perceived ease-of-use is positively correlated with attitudes towards AVs.

H4: Perceived value is positively correlated with attitudes towards AVs.

Developing on the notion of perceived risk (Lim et al, 2018; Wang et al, 2018; Alemi et al, 2019; Wang et al, 2019; AlHamad et al., 2021a\&b; Al-Maroof et al., 2021a\&b), research suggests (Schoettle \& Sivak, 2014; Kyriakidis et al., 2015; Hulse et al., 2018; Kaur and Rampersad, 2018) this is a major point of consideration as AVs have additional variables within this category such as privacy, technical glitches, hacking and security. These concerns will be addressed using the following two hypotheses:

H5: Perceived safety is positively correlated with attitudes towards AVs.

$\mathbf{H}_{6}$ : Perceived risk is negatively correlated with attitudes towards AVS.

Environmental concerns are frequently cited as a significant factor (Krueger et al., 2016; Haboucha et al., 2017; Alshurideh et al., 2019; Alameeri et al., 2020), affirming the previously mentioned research (Alemi et al, 2018; Wang et al, 2018), highlighting it is a key consideration. To test these assertions, a hypothesis is as follows:

$\mathbf{H}_{7}$ : Pro-environmentalism is positively correlated with attitudes towards AVs. 
Another recurring theme in the previous literature is both awareness and attitudes towards technology (Schoettle \& Sivak, 2014; Bansal, Kockelman \& Singh, 2016; Nazari, Noruzoliaee \& Mohammadian, 2018). Meanwhile, a common concern was raised in the artificial intelligence literature (Herzfeld, 2002; Dekker, Salomons \& Waal, 2017) which does not yet appear to be a significant focus of AV attitudinal research, is the threat of human replacement. A study by Pakusch et al. (2020), did however find that the fate of traditional taxi drivers was not a significant influencing factor for millennials. The following hypothesis will be used to evaluate these claims:

\section{H8: Pro-technology beliefs are positively correlated with attitudes towards AVs.}

As previously identified in ride-hailing literature (Peng et al, 2014; Fleischer and Wåhlin, 2016; Zhu, So and Hudson, 2017; Min So \& Jeong, 2018), subjective norms and behavioural control frequently appear in AV research (Panagiotopoulos \& Dimitrakopoulos, 2018; Acheampong \& Cugurullo, 2019) and are therefore key variables to explore. As such, the two hypotheses below will be used:

H9: Subjective norms are positively correlated with attitudes towards AVS.

H10: Perceived behavioural control is positively correlated with attitudes towards AVS.

In adherence to the theory of Planned Behaviour (1985) model, intentions to use the service will also be explored. Current studies have found overall attitudes (Chen, 2019), subjective norms (Kelkel, 2015; Panagiotopoulos and Dimitrakopoulos, 2018), and perceived behavioural control (Lee et al, 2019) all to display a positive relationship with behavioural intentions. As such, the final three hypotheses for this study are as follows:

$\mathbf{H}_{11}$ : Attitudes towards AVs are positively correlated with intentions to use AVs.

H12: Subjective norms are positively correlated with intentions to use AVs.

$\mathbf{H}_{13}$ : Perceived behavioural control is positively correlated with intentions to use AVS.

From the literature that has been reviewed above, Fig. 1 below is developed to measure attitudes towards AVs and to predict respondents' behaviour.

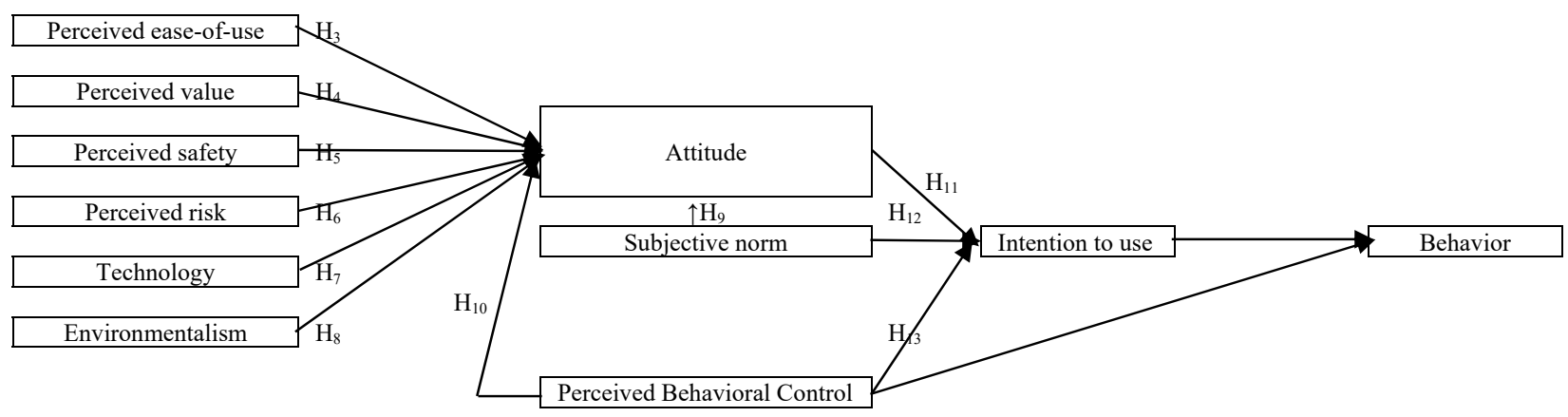

Fig. 1. Proposed Model

The figure above is primarily based on the theory of Planned Behaviour (1985), with an additional six salient belief variables in-line with the Fishbein Expectancy-value Model (1963) and the Three-component Model (1960), which indicate beliefs are the foundations of attitude formation. Each of the six belief variables (perceived ease-of-use, perceived value, perceived safety, perceived risk, technology, and environmentalism) and two mediating variables (subjective norms and perceived behavioural control) were identified in the AV literature during this section, and thirteen respective hypotheses have been created to test these relationships.

\section{Methods}

\subsection{Data collection and study sample}

Data collection process took place during the summer of 2021. An online survey was designed to collect quantitative data through the use of a Likert scale. The online survey software known as Qualtrics was used to build the survey and allow for easy distribution and data collection. This software is useful as it allows for a simple, interactive design, where all participants feel comfortable whilst completing the questionnaire. Qualtrics provides an online link in order to share the questionnaire with the intended sample, tracking response rate and collecting the data from the online platform. The online survey was distributed using the first authors' social media page. Indeed, this offers an efficient, and cost-effective approach for obtaining responses (Dusek, Yurova and Ruppel, 2015). Appendix 1 outlines the questions which were asked in the survey, and the respective sources they were adapted from. 
The sample targeted 18-24-year-old, ride-hailing users who live in the United Kingdom. This group is believed to be the most frequent users of application-based taxi services, and they are likely to be the first to gain access to autonomous taxis (Freedman et al., 2018; Mazareanu, 2019). In total, 193 responses were obtained however, due to incomplete items, 42 were discarded leaving 151 valid responses. Of the valid responses, $69.5 \%$ were male and $30.5 \%$ were female. This was far less equal than would be desirable for a balanced data set, which may be a consequence of using a self-administered, online survey with a convenience sampling approach (Muijis, 2010).

\subsection{Data analysis}

Univariate analysis was first used to consider variables individually, and present simple, descriptive statistics including averages, measures of spread and variation in responses; visual representations of this data (Greasley, 2007; Bryman \& Cramer, 2012). Bivariate analysis was also used to establish whether a relationship exists between the variables in question; this is considered the most significant component of a quantitative study as the results can support or reject the identified hypotheses (Muijs, 2010; Bryman \& Cramer, 2012). As the focus of this study is to measure the relationship between attitudes, beliefs (perceived ease-of-use, perceived value, perceived safety, perceived risk, technology, environmentalism), and mediating variables (subjective norms, perceived behavioural control); as such, correlation testing will be used. Correlation is a technique which seeks to measure the extent to which an independent variable influences the dependent variable (Greasley, 2007). There are a range of tests available to perform this analysis, however as a Likert scale is used, producing data which is ranked but without equal intervals, the appropriate method is Spearman's Rank (Treiman, 2014). This test will be performed within SPSS to produce a correlation coefficient which, when tested against an appropriate significance level, will determine whether a relationship exists (DeCoster and Claypool, 2004). This test will be used to measure the correlation between the dependent variable, which is the overall attitude held by participants towards autonomous taxis, and the independent variables, which consist of the defined set of beliefs, subjective norms, perceived behavioural control and intention to use the service; from the data generated, it will be possible to accept or reject the hypotheses identified in the previous chapter (Muijs, 2010). Next, each independent variable is composed of multiple questions in line with Fishbein and Ajzen's (1977) analysis, stating this approach will increase the accuracy in determining attitudes. Therefore, before performing the correlation test, Cronbach's alpha will be used to measure the internal consistency between the questions to allow for a composite data set to be formed for each independent variable (Bryman \& Bell, 2011).

\section{Results}

\subsection{Factors associated with the intent to use autonomous vehicles within the UK taxi industry}

The purpose of this study was to determine attitudes held towards AVs and understand their impact on intentions to use the service. Table 1 provides an overview of the results, detailing the mean, standard deviation, and Cronbach's alpha for each category.

\section{Table 1}

The summary of some basic statistics

\begin{tabular}{|c|c|c|}
\hline Items & Mean & Standard Deviation \\
\hline Overall Attitude & 3.45 & 0.95 \\
\hline Overall, my attitude towards self-driving vehicles is & 3.45 & 0.95 \\
\hline Perceived Ease-of-use $(\alpha=0.700)$ & 4.106 & 0.66038 \\
\hline I think using a self-driving taxi would be easy for me. & 3.58 & 0.969 \\
\hline Using a ride-hailing application like Uber is straightforward. & 4.5 & 0.711 \\
\hline It would be easy to book a self-driving taxi if it used the same ride-hailing application. & 4.24 & 0.806 \\
\hline Perceived Value $(\alpha=0.852)$ & 3.5613 & 0.86937 \\
\hline I think there will be benefits to using self-driving taxis. & 3.72 & 0.988 \\
\hline I think self-driving taxis will be useful for getting around. & 3.86 & 0.895 \\
\hline I think self-driving taxis will improve my transport options. & 3.28 & 1.09 \\
\hline I think I would enjoy the experience of using a self-driving taxi. & 3.38 & 1.182 \\
\hline Perceived Safety $(\alpha=0.866)$ & 3.3311 & 0.88955 \\
\hline I think self-driving taxis will be safe when they are made available. & 3.33 & 1.075 \\
\hline I think self-driving taxis will come with reliable safety features which have been tested thoroughly. & 3.86 & 0.98 \\
\hline I would trust a self-driving taxi to get me to my destination safely. & 3.32 & 1.099 \\
\hline I think self-driving taxis will be safer than regular taxis. & 2.81 & 1.057 \\
\hline Perceived Risk $(\alpha=0.577)$ & 3.4062 & 0.70437 \\
\hline $\begin{array}{l}\text { I think there will be a greater risk of something going wrong when using a self-driving taxi, compared to a regular } \\
\text { taxi. }\end{array}$ & 3.38 & 0.992 \\
\hline Self-driving taxis will be vulnerable to hacking. & 3.36 & 0.934 \\
\hline Self-driving taxis will experience technical glitches whilst driving. & 3.48 & 0.893 \\
\hline I will have to give up some digital privacy to use a self-driving taxi. & 3.32 & 1.022 \\
\hline Environmentalism $(\alpha=\mathbf{0 . 8 5 5})$ & 3.9884 & 0.76558 \\
\hline Global warming is a concern for me. & 4.32 & 0.778 \\
\hline I would change my behaviour for environmental reasons. & 4.18 & 0.767 \\
\hline I would change my preferred method of transport if there was a more environmentally friendly option. & 3.91 & 0.996 \\
\hline
\end{tabular}


Table 1

The summary of some basic statistics (Continued)

\begin{tabular}{|c|c|c|}
\hline Items & Mean & Standard Deviation \\
\hline Technology $(\alpha=0.622)$ & 4.1291 & 0.68182 \\
\hline I keep up to date with new technologies. & 3.92 & 0.876 \\
\hline I knew what a self-driving car was before taking this survey. & 4.22 & 0.886 \\
\hline My attitude towards technology is favourable. & 4.1 & 0.87 \\
\hline I think technological advancements are beneficial to society. & 4.28 & 0.834 \\
\hline I think technology will replace humans and take our jobs. & 3.1 & 1.124 \\
\hline Subjective Norms $(\alpha=0.793)$ & 3.181 & 0.7895 \\
\hline I would use a self-driving taxi if people I respect do the same. & 3.17 & 0.996 \\
\hline I would like to be seen in a self-driving taxi by my friends/ family. & 2.89 & 0.865 \\
\hline People in my social group would like to use self-driving taxis. & 3.48 & 0.951 \\
\hline Perceived Behavioural Control $(\alpha=0.334)$ & 4.0728 & 0.59553 \\
\hline It would be my decision whether I used a self-driving taxi or not. & 4.32 & 0.698 \\
\hline If I wanted to, I would be able to afford a trip in a self-driving taxi. & 3.82 & 0.833 \\
\hline Intention to Use & 3.32 & 1.061 \\
\hline When they are made available, I intend to use self-driving taxis. & 3.32 & 1.061 \\
\hline
\end{tabular}

Overall, attitudes towards AVs from this sample were positive. Looking closer into this question and in line with the role of gender, as identified in the literature review, male respondents held more positive attitudes than females. This is evident through a cumulative $53.3 \%$ positive male attitudes, compared with $43.5 \%$ from female participants. Interestingly, however, female users were more likely to be "neutral" and males accounted for all "very negative responses", suggesting that males were more polarised than females. Perceived ease-of-use produced the second highest mean of 4.1060; suggesting this was an area that participants were comfortable. Perceived value was overall, slightly positive with a mean response of 3.5613 . Perceived safety elicited a broad range of responses. The most significant result came from the question 'I think self-driving taxis will be safer than regular taxis', which was the most negative mean of the study, scoring 2.81 . This was due to $43 \%$ suggesting they 'disagree' or 'strongly disagree' with the statement and $33.1 \%$ unsure - only $23.8 \%$ responded positively. This is a very important result as reducing road fatalities is one of the major anticipated benefits of AVs and it is, therefore, significant that this sample holds opposing beliefs. The mean response for perceived risk was 3.4062 which suggests respondents feel there will be a risk to using self-driving taxis. Attitudes towards technology were incredibly positive, receiving the highest mean score of 4.1291. Subjective norms received the lowest category mean of 3.1810, suggesting that individuals were undecided whether social influence would play a role in their decision to use a self-driving taxi.

perceived behavioural control received a positive score with a mean of 4.0728. In addition, this category received the lowest standard deviation, suggesting that the group were confident in their beliefs. Whilst intention to use received a slightly positive mean score of 3.32, this was a polarising question as is shown by a standard deviation of 1.061 and displayed visually below. A cumulative $49.7 \%$ indicated they intend to use the service however a significant $22.6 \%$ would not - leaving $27.8 \%$ undecided.

\subsection{Correlation analysis}

To measure the relationship between a dependent variable and several independent variables which belong to a single category, a composite series is often used (Babbie et al., 2018). Cronbach's alpha is often used to measure the internal reliability between the items and determine whether it is appropriate to merge the series (Gliem \& Gliem, 2003). Items with a coefficient of 0.7 or above are widely accepted as consistent and can be considered a single variable (Dunn et al., 2014; George \& Mallery, 2019).

As set out in Table 1, perceived ease-of-use (0.700), perceived value (0.852), perceived safety (0.866), environmentalism $(0.855)$ and subjective norms $(0.793)$ all received alpha's which satisfy this condition. Technology initially received 0.622 however, when the item 'I think that technology will replace humans and take our jobs' is removed, the alpha value increases to 0.795 . Perceived risk generated a value of 0.577 which was only improved to 0.608 upon removal of the item 'I think I will have to give up some digital privacy to use a self-driving taxi'. Whilst this is below the ideal range, researchers have suggested coefficients above 0.6 may be satisfactory, offer moderate consistency and may be useful for research (Ponterotto \& Ruckdeschel, 2007). The revised items will therefore be used to create a composite series; however, it is acknowledged this result is to be considered less accurate. Perceived behavioural control however, generated an alpha of 0.334 which is unacceptable. They will therefore be considered individually, labelled as; (1) 'If I wanted to, I would be able to afford a trip in a self-driving taxi'; and (2) 'it would be my decision whether I used a self-driving taxi or not'. Once the composite series was made, a spearman's rank test was performed to measure the relationships between the variables; producing evidence to support or reject the hypotheses identified in chapter 2. Whilst there are no definitive boundaries set for correlation coefficients, the following table provides guidance to help interpret the values produced. 
Table 2

Correlation Coefficient Ranges (Mujis, 2010)

\begin{tabular}{ll}
\hline Size $( \pm \rho)$ & Relationship \\
\hline $0.0<\rho<0.1$ & Weak \\
$0.1 \leq \rho<0.3$ & Modest \\
$0.3 \leq \rho<0.5$ & Moderate \\
$0.5 \leq \rho<0.8$ & Strong \\
$0.8 \leq \rho \leq 1.0$ & Very Strong \\
\hline
\end{tabular}

Table 3

Spearman's Rank Correlations

\begin{tabular}{llll}
\hline Items & & & Spearman's $(\rho)$ \\
\hline Perceived Ease-of-use & $\rightarrow$ & Overall Attitude & $.579^{* *}$ \\
Perceived Value & $\rightarrow$ & Overall Attitude & $.607^{* *}$ \\
Perceived Safety & $\rightarrow$ & Overall Attitude & $.533^{* *}$ \\
Perceived Risk & $\rightarrow$ & Overall Attitude & $-.388^{* *}$ \\
Environmentalism & $\rightarrow$ & Overall Attitude & .000 \\
Technology & $\rightarrow$ & Overall Attitude & .000 \\
Subjective Norm & $\rightarrow$ & Overall Attitude & .000 \\
Perceived Behavioural Control (1) & $\rightarrow$ & Overall Attitude & $.0165^{* *}$ \\
Perceived Behavioural Control (2) & $\rightarrow$ & Overall Attitude & $.413^{* *}$ \\
Overall Attitude & $\rightarrow$ & Intention to Use & $.305^{* *}$ \\
Subjective Norm & $\rightarrow$ & Intention to Use & .066 \\
Perceived Behavioural Control (1) & $\rightarrow$ & Intention to Use & $.663^{* *}$ \\
Perceived Behavioural Control (2) & $\rightarrow$ & Intention to Use & $.0009^{* *}$ \\
\hline
\end{tabular}

\subsection{Hypothesis Testing}

From the correlation results in the table above, it is now possible to assess the hypotheses identified during the literature review

$H_{1}$ : Attitudes towards AVs are positive.

As outlined in 4.3, 50.3\% of participants suggested their attitudes were either 'positive' or 'very positive', producing a mean score of 3.45 which substantiates this hypothesis.

$\mathrm{H}_{2}$ : Male respondents have more favourable attitudes towards $A V S$.

The results show males responded more positively than females with cumulative positive responses of $53.3 \%$ and $43.5 \%$ respectively. To further support this hypothesis, the mean male response was 3.486 whereas it was slightly less at 3.370 for female participants.

$H_{3}$ : Perceived ease-of-use is positively correlated with attitudes towards AVS.

This test produced a correlation coefficient of .579 and was deemed significant at the 0.01 level. As $\rho>0.5$, this test showed a strong positive correlation between the variables and supports this hypothesis.

$H_{4}$ : Perceived value is positively correlated with attitudes towards $A V_{S}$.

This test produced a correlation coefficient of .607 , displaying a strong positive relationship. This was significant at the 0.01 level - allowing for this hypothesis to be accepted.

$H_{5}:$ Perceived safety is positively correlated with attitudes towards AVs.

This hypothesis can also be confirmed due to a correlation coefficient of .533 which can be categorized as a strong positive relationship and was significant at the 0.01 level.

$H_{6}:$ Perceived risk is negatively correlated with attitudes towards AVs.

A coefficient of -.388 suggests that perceived risk is negatively correlated with overall attitudes however as $\rho>-0.5$ the relationship can only be described as moderate. The test was, however, significant at the 0.01 level, indicating that whilst only moderate, there is only a $1 \%$ chance no relationship exists. 
$H_{7}$ : Pro-environmentalism is positively correlated with attitudes towards $A V S$.

Environmentalism has the lowest coefficient of tests that were significant; scoring .195 which was significant at the 0.05 level. Whilst the relationship can be described as modest, the increased significance level suggests there is a much larger possibility that no relationship exists.

$H_{8}$ : Pro-technology beliefs are positively correlated with attitudes towards AVs.

Technological beliefs displayed a strong relationship with attitudes towards AVs, with a correlation coefficient of .526. This was significant at the 0.01 level and confirms the research hypothesis.

$H_{9}$ : Subjective norms are positively correlated with attitudes towards AVS.

Subjective norms were found to have a modest correlation with a coefficient of .413 . this was again, significant at the 0.01 which suggests the hypothesis is true.

$H_{10}:$ Perceived behavioural control is positively corelated with attitudes towards AVS.

Item (1) displayed a moderate correlation with overall attitudes towards AVs with a coefficient of .305 which was significant at the 0.01 level - suggesting the ability to afford the service had a moderate influence on attitudes. Item (2) however, only produced a coefficient of .066 and was not found to be significant.

$H_{11}:$ Attitudes towards AVs are positively correlated with intentions to use AVs.

The correlation between overall attitudes and intention to use was the highest at .663 - suggesting this is the most important variable in predicting behaviour regarding AVs. The result was significant at the 0.01 level and confirms the validity of the hypothesis.

$H_{12}$ : Subjective norms are positively correlated with intentions to use AVs.

Subjective norms produced the second highest correlation with intention to use at .609, suggesting they are strongly correlated variables. The hypothesis can therefore be accepted with significance at the 0.01 level.

$H_{13}:$ Perceived behavioural control is positively correlated with intentions to use AVS.

Item (1) displayed a moderate correlation with intentions to use the service, producing a value of .322 which was significant at the 0.01 level. Item (2) however, generated a correlation coefficient of -.069 which was a weak and interestingly a negative score, which was not significant.

\section{Discussion}

An autonomous vehicle (AV) can drive independently, without human supervision, using onboard software and sensors (McBride, 2016; Surden and Williams, 2016). This innovation is predicted to reduce road-traffic accidents, lower transport costs and reduce emissions. However, the literature points to some concerns over the safety of these vehicles which may lead to the formation of negative attitudes (Shariff et al, 2017). Consequently, the primary aim of this research was to determine attitudes held towards AVs and understand their impact on intentions to use the service. The present study takes a novel approach by focusing on ride-hailing users, within the context of application-based taxi service as current research predicts that users of these services will be the first to experience this new automotive technology due to the high cost of personal ownership. Specifically, the study will focus on the UK consumer (18-24-year-olds) attitudes as this age group is thought to be the most frequent users of ride-hailing applications.

The study results indicated that respondents overall had positive attitudes towards using the AVs. This result is in line with the findings of other studies (Payre et al., 2014; Schoettle and Sivak, 2014; Hulse, Xie and Galea, 2018; Liljamo et al., 2018). This result was expected as the focus of this study has been of ride-hailing users, and it will be possible to book an AV through the same app. Moreover, the results of this study indicated that the three constructs perceived perceived ease-of-use, perceived value and perceived safety impact consumer attitudes toward use AVs. These results are in line with those of previous studies Cugurullo's, (2019), Panagiotopoulos and Dimitrakopoulos, 2018, Hilgarter and Granig, 2020.

A key result, however, was a negative response to 'I think that self-driving taxis will be safer than regular taxis'; this is important as improved safety is thought to be one of the main benefits of this technology (Lee et al, 2019). This confirms the work by Liljamo et al., (2018), which found safety to be the largest concern for individuals. This result is so interesting as participants also indicated that they agreed AV taxis would 'come with reliable safety features which had been tested 
thoroughly', which at first glance may seem contradictory. This however, highlights that the chosen sample were not aware of, or did not believe, that self-driving technology would be safer than their human counterparts and this should be a focus of marketing material. When tested against overall attitudes, a strong positive relationship was observed. This result supports the findings in other studies (Kelkel, 2015; Chen, 2019; Ro and Ha, 2019), and suggests perceived safety is positively correlated with overall attitudes. Overall, based on the study results, the Theory of Planned Behaviour (1985) by Fishbein and Ajzen (1975) appears to be accurate. All pathways were found to be significant, and it is therefore recommended this model is used in further studies on this topic.

\section{Conclusions and implications}

The aim of this research was to determine the attitudes which are held towards autonomous vehicles and understand their impact on intentions to use the service. From the literature review, Ajzen's (1985) theory of Planned Behaviour was chosen as the framework for this study as it has been extensively used to measure attitudes and predict behavioural intentions. In the present study, an online based survey was conducted among 18-24 years old participants, generating 151 responses.

The main contribution of this study is providing data to a new, and rapidly evolving field of research and thus the findings of the present study contribute to ongoing research related to consumers attitudes of AVs. Managerially, companies that focus on developing and implementing AV taxis need to focus more on the safety benefits of such vehicles. A campaign addressing these concerns is therefore recommended. Additionally, many respondents indicated they were unsure whether they '...would be able to afford a trip in a self-driving taxi'. This would indicate that more information regarding the cost of the service may lead to more favourable attitudes.

Ultimately, as the implementation of this technology is years away, a major limitation is the lack of knowledge or opinions regarding this innovation (Ghannajeh et al., 2015; Al Suwaidi et al., 2020; Al Naqbia et al., 2020). As set out by Ro and Ha (2019), respondents have not yet experienced AV taxis and it is, therefore, difficult for them to hold strong opinions. Hence, there is also a clear need for qualitative research to understand the reasoning behind the recorded data. Pettigrew et al. (2019) observed anxiety and fear to be the reason for some females to report negative attitudes towards AVs, however, additional research should be conducted to understand these results in more depth, and potentially highlight how unfavourable attitudes may be changed.

\section{References}

Acheampong, R.A., \& Cugurullo, F., (2019). Capturing the behavioural determinants behind the adoption of autonomous vehicles: Conceptual frameworks and measurement models to predict public transport, sharing and ownership trends of self-driving cars. Transportation research part F: traffic psychology and behaviour, 62, 349-375.

Abuhashesh, M. Y., Alshurideh, M. T., \& Sumadi, M. (2021). The effect of culture on customers' attitudes toward Facebook advertising: the moderating role of gender. Review of International Business and Strategy, 31(3), 416-437.

Ahmad, A., Alshurideh, M., Al Kurdi, B., Aburayya, A., \& Hamadneh, S. (2021). Digital transformation metrics: a conceptual view. Journal of Management Information and Decision Sciences, 24(7), 1-18.

Ajzen, I., (1989). Attitude structure and behavior. Attitude Structure and Function, 241, 231-274.

Ajzen, I., (2008). Consumer attitudes and behavior. University of Massachusetts - Amherst. 525-548.

Akour, I., Alshurideh, M., Al Kurdi, B., Al Ali, A., \& Salloum, S. (2021). Using machine learning algorithms to predict people's intention to use mobile learning platforms during the COVID-19 pandemic: machine learning approach. JMIR Medical Education, 7(1), e24032.

Alameeri, K., Alshurideh, M., Al Kurdi, B., \& Salloum, S. A. (2020, October). The effect of work environment happiness on employee leadership. In International Conference on Advanced Intelligent Systems and Informatics (pp. 668-680). Springer, Cham.

Alameeri, K. A., Alshurideh, M. T., \& Al Kurdi, B. (2021). The Effect of Covid-19 Pandemic on Business Systems' Innovation and Entrepreneurship and How to Cope with It: A Theatrical View. The Effect of Coronavirus Disease (COVID-19) on Business Intelligence, 334, 275-288.

Albarracin, D., Johnson, B. and Zanna, M., (2005). The Handbook Of Attitudes. Mahwah, N.J.: Lawrence Erlbaum Associates.

Alemi, F., Circella, G., Handy, S. and Mokhtarian, P., (2018). What influences travelers to use Uber? Exploring the factors affecting the adoption of on-demand ride services in California. Travel Behaviour and Society, 13, pp.88-104.

Al-Dhuhouri, F. S., Alshurideh, M., Al Kurdi, B., \& Salloum, S. A. (2020, October). Enhancing our understanding of the relationship between leadership, team characteristics, emotional intelligence and their effect on team performance: A Critical Review. In International Conference on Advanced Intelligent Systems and Informatics (pp. 644-655). Springer, Cham.

Al-Dmour, H., Alshuraideh, M., \& Salehih, S. (2014). A study of Jordanians' television viewers habits. Life Science Journal, 11(6), 161-171.

AlHamad, M., Akour, I., Alshurideh, M., Al-Hamad, A., Kurdi, B., \& Alzoubi, H. (2021a). Predicting the intention to use google glass: A comparative approach using machine learning models and PLS-SEM. International Journal of Data and Network Science, 5(3), 311-320. 
Al-Hamad, M., Mbaidin, H., AlHamad, A., Alshurideh, M., Kurdi, B., \& Al-Hamad, N. (2021b). Investigating students' behavioral intention to use mobile learning in higher education in UAE during Coronavirus-19 pandemic. International Journal of Data and Network Science, 5(3), 321-330.

Al Kurdi, B., Alshurideh, M., \& Salloum, S. A. (2020). Investigating a theoretical framework for e-learning technology acceptance. International Journal of Electrical and Computer Engineering (IJECE), 10(6), 6484-6496.

Al Kurdi, B., Alshurideh, M., Salloum, S., Obeidat, Z., \& Al-dweeri, R. (2020). An empirical investigation into examination of factors influencing university students' behavior towards elearning acceptance using SEM approach.

Al-Maroof, R. S., Alshurideh, M. T., Salloum, S. A., AlHamad, A. Q. M., \& Gaber, T. (2021a). Acceptance of Google Meet during the spread of Coronavirus by Arab university students. In Informatics (Vol. 8, No. 2, p. 24). Multidisciplinary Digital Publishing Institute.

Al-Maroof, R., Ayoubi, K., Alhumaid, K., Aburayya, A., Alshurideh, M., Alfaisal, R., \& Salloum, S. (2021b). The acceptance of social media video for knowledge acquisition, sharing and application: A comparative study among YouYube users and TikTok users' for medical purposes. International Journal of Data and Network Science, 5(3), 197.

Almaazmi, J., Alshurideh, M., Al Kurdi, B., \& Salloum, S. A. (2020, October). The effect of digital transformation on product innovation: a critical review. In International Conference on Advanced Intelligent Systems and Informatics (pp. 731-741). Springer, Cham.

Al Naqbi, E., Alshurideh, M., AlHamad, A., \& Al, B. (2020). The impact of innovation on firm performance: a systematic review. International Journal Innovation Creative Change, 14(5), 31-58.

Alsharari, N. M., \& Alshurideh, M. T. (2020). Student retention in higher education: the role of creativity, emotional intelligence and learner autonomy. International Journal of Educational Management. 35(1), 233-247.

Alshurideh, M., Al Kurdi, B., \& Salloum, S. A. (2019, October). Examining the main mobile learning system drivers' effects: A mix empirical examination of both the Expectation-Confirmation Model (ECM) and the Technology Acceptance Model (TAM). In International Conference on Advanced Intelligent Systems and Informatics (pp. 406-417). Springer, Cham.

Alshurideh, M., Kurdi, B. A., Shaltoni, A. M., \& Ghuff, S. S. (2019). Determinants of pro-environmental behaviour in the context of emerging economies. International Journal of Sustainable Society, 11(4), 257-277.

Alshurideh, M. T., Al Kurdi, B., \& Salloum, S. A. (2021). The moderation effect of gender on accepting electronic payment technology: a study on United Arab Emirates consumers. Review of International Business and Strategy, 31(3), $375-396$.

Alshurideh, M., Gasaymeh, A., Ahmed, G., Alzoubi, H., \& Kurd, B. (2020). Loyalty program effectiveness: Theoretical reviews and practical proofs. Uncertain Supply Chain Management, 8(3), 599-612.

Alshurideh, M., Nicholson, M., \& Xiao, S. (2012). The effect of previous experience on mobile subscribers' repeat purchase behaviour. European Journal of Social Sciences, 30(3), 366-376.

Alshurideh, M., Salloum, S. A., Al Kurdi, B., \& Al-Emran, M. (2019, February). Factors affecting the social networks acceptance: an empirical study using PLS-SEM approach. In Proceedings of the 2019 8th International Conference on Software and Computer Applications (pp. 414-418).

Alsuwaidi, M., Alshurideh, M., Al Kurdi, B., \& Salloum, S. A. (2020, October). Performance appraisal on employees' motivation: a comprehensive analysis. In International Conference on Advanced Intelligent Systems and Informatics (pp. 681693). Springer, Cham.

Al Suwaidi, F., Alshurideh, M., Al Kurdi, B., \& Salloum, S. A. (2020, October). The impact of innovation management in SMEs performance: a systematic review. In International Conference on Advanced Intelligent Systems and Informatics (pp. 720-730). Springer, Cham.

Araujo, L., Manson, K. and Spring, M. (2012). Self-driving cars. A case study in making new markets-London, UK: Big Innovation Centre, 9.

Argyriou, E., \& Melewar, T.C. (2011). Consumer attitudes revisited: A review of attitude theory in marketing research. International Journal of Management Reviews, 13(4), 431-451.

Arvola, A., Lähteenmäki, L. and Tuorila, H. (1999). Predicting the intent to purchase unfamiliar and familiar cheeses: The effects of attitudes, expected liking and food neophobia. Appetite, 32(1), 113-126.

Babbie, E., Wagner III, W.E. and Zaino, J. (2018). Adventures in social research: Data analysis using IBM SPSS statistics. Sage Publications.

Bansal, P., Kockelman, K.M., \& Singh, A. (2016). Assessing public opinions of and interest in new vehicle technologies: An Austin perspective. Transportation Research Part C: Emerging Technologies, 67, 1-14.

BBC News. (2020). Self-driving car tests begin on Oxford's roads. [online] Available at: <https://www.bbc.co.uk/news/ukengland-oxfordshire-54744656> [Accessed 1 April 2021].

Breckler, S.J. (1984). Empirical validation of affect, behavior, and cognition as distinct components of attitude. Journal of Personality and Social Psychology, 47(6), 1191-1205.

Bogardus, E.S. (1931). Fundamentals of social psychology.

Bryman, A., \& Cramer, D. (2012). Quantitative data analysis with IBM SPSS 17, 18 \& 19: A guide for social scientists. Routledge.

Bryman, A., \& Bell, E., (2011). Business Research Methods. $3^{\text {rd }}$ ed. Oxford: Oxford University Press.

Charness, N., Yoon, J.S., Souders, D., Stothart, C., \& Yehnert, C. (2018). Predictors of attitudes toward autonomous vehicles: The roles of age, gender, prior knowledge, and personality. Frontiers in Psychology, 9, 1-9. 
Choi, J.K., \& Ji, Y.G., (2015). Investigating the importance of trust on adopting an autonomous vehicle. International Journal of Human-Computer Interaction, 31(10), 692-702.

Crano, W.D., \& Prislin, R., (2011). Attitudes and Attitude Change: The Fourth Peak. In Attitudes and attitude change (pp. 17-30). Psychology Press.

Daily, M., Medasani, S., Behringer, R., \& Trivedi, M. (2017). Self-driving cars. Computer, 50(12), 18-23.

Davidson, P., \& Spinoulas, A., (2015), July. Autonomous vehicles: what could this mean for the future of transport. In Australian Institute of Traffic Planning and Management (AITPM) National Conference, Brisbane, Queensland.

Day, G.S. (1972). Evaluating models of attitude structure. Journal of Marketing Research, 9(3), 279-286.

DeCoster, J., \& Claypool, H., (2004). Data analysis in SPSS. Retrieved October, 2, p.2015.

Dekker, F., Salomons, A., \& Waal, J.V.D., (2017). Fear of robots at work: the role of economic self-interest. Socio-Economic Review, 15(3), 539-562.

Droba, D.D. (1933). The nature of attitude. The Journal of Social Psychology, 4(4), 444-463.

Dusek, G.A., Yurova, Y.V., \& Ruppel, C.P., (2015). Using social media and targeted snowball sampling to survey a hard-toreach population: A case study. International Journal of Doctoral Studies, 10(1), 279-299.

Fazio, R.H. (1986). How do attitudes guide behavior. Handbook of motivation and cognition: Foundations of social behavior, $1,204-243$.

Fazio, R.H. (2007). Attitudes as object-evaluation associations of varying strength. Social cognition, 25(5), 603-637.

Fazio, R.H. (1987). Self-perception theory: A current perspective. In Social Influency: The Ontario Symposium, 5, 129-50.

Feng, G., Kong, G., \& Wang, Z. (2017). We are on the way: Analysis of on-demand ride-hailing systems. Available at SSRN 2960991.

Fishbein, M., \& Ajzen, A. (1980). Understanding Attitudes and Predicting Social Behaviour. Preventive-Hall. Inc., Englewood Cliffs.

Fiske, S.T., Gilbert, D.T. \& Lindzey, G. eds. (2010). Handbook of Social Psychology, Volume 1 (Vol. 1). John Wiley \& Sons.

Fleischer, A., \& Wåhlin, C., (2016). Want to take a ride with me?: The Intention of Generation Y to Use Uber.

Freedman, I.G., Kim, E., \& Muennig, P.A. (2018). Autonomous vehicles are cost-effective when used as taxis. Injury Epidemiology, 5(1), 1-8.

Ghannajeh, A. M., AlShurideh, M., Zu'bi, M. F., Abuhamad, A., Rumman, G. A., Suifan, T., \& Akhorshaideh, A. H. O. (2015). A qualitative analysis of product innovation in Jordan's pharmaceutical sector. European Scientific Journal, 11(4), 474-503.

Greenwald, A.G. (1989). Why attitudes are important: Defining attitude and attitude theory 20 years later.

Goodmonson, C., \& Glaudin, V., (1971). The relationship of commitment-free behavior and commitment behavior: A study of attitude toward organ transplantation. Journal of Social Issues, 27(4), 171-183.

Greasley, P. (2007). Quantitative data analysis using SPSS: an introduction for health \& social science. McGraw-Hill Education (UK).

Haboucha, C.J., Ishaq, R., \& Shiftan, Y. (2017). User preferences regarding autonomous vehicles. Transportation Research Part C: Emerging Technologies, 78, 37-49.

Hamadneh, S., Pedersen, O., \& Al Kurdi, B. (2021). An Investigation of The Role of Supply Chain Visibility into The Scottish Blood Supply Chain. Journal of Legal, Ethical and Regulatory Issues, 24, 1-13.

Hamadneh, S., Hassan, J., Alshurideh, M., Al Kurdi, B., \& Aburayya, A. (2021). The effect of brand personality on consumer self-identity: the moderation effect of cultural orientations among British and Chinese consumers. Journal of Legal, Ethical and Regulatory, 24, 1-14.

Herzfeld, N. (2002). Creating in our own image: Artificial intelligence and the image of God. Zygon ${ }^{\circledR}, 37(2), 303-316$.

Hilgarter, K., \& Granig, P., (2020). Public perception of autonomous vehicles: a qualitative study based on interviews after riding an autonomous shuttle. Transportation research part F: traffic psychology and behaviour, 72, $226-243$.

Hovland, C., \& Rosenberg, M. (1960). Attitude Organization and change: an analysis of consistency among attitude components. New Haven: Yale University Press.

Hudson, J., Orviska, M., \& Hunady, J., (2019). People's attitudes to autonomous vehicles. Transportation research part A: policy and practice, 121, 164-176.

Hulse, L.M., Xie, H. and Galea, E.R., (2018). Perceptions of autonomous vehicles: Relationships with road users, risk, gender and age. Safety Science, 102, 1-13.

Kaur, K., \& Rampersad, G., (2018). Trust in driverless cars: Investigating key factors influencing the adoption of driverless cars. Journal of Engineering and Technology Management, 48, 87-96.

Kelkel, R., (2015). Predicting consumers' intention to purchase fully autonomous driving systems: which factors drive acceptance? (Doctoral dissertation).

König, M., \& Neumayr, L., (2017). Users' resistance towards radical innovations: The case of the self-driving car. Transportation research part $F$ : traffic psychology and behaviour, 44, 42-52.

Krueger, E.T., \& Reckless, W.C., (1931). Social Psychology. vii, 578. New York:

Kurdi, B., \& Alshurideh, M. (2020a). Employee retention and organizational performance: Evidence from banking industry. Management Science Letters, 10(16), 3981-3990.

Kurdi, B., Alshurideh, M., \& Alnaser, A. (2020b). The impact of employee satisfaction on customer satisfaction: Theoretical and empirical underpinning. Management Science Letters, 10(15), 3561-3570. 
Kurdi, B. A., Alshurideh, M., Nuseir, M., Aburayya, A., \& Salloum, S. A. (2021, March). The effects of subjective norm on the intention to use social media networks: an exploratory study using PLS-SEM and machine learning approach. In International Conference on Advanced Machine Learning Technologies and Applications (pp. 581-592). Springer, Cham.

Kyriakidis, M., Happee, R., \& de Winter, J.C. (2015). Public opinion on automated driving: Results of an international questionnaire among 5000 respondents. Transportation research part F: traffic psychology and behaviour, 32, $127-140$.

Lada, S., Tanakinjal, G.H., \& Amin, H., (2009). Predicting intention to choose halal products using theory of reasoned action. International Journal of Islamic and Middle Eastern Finance and Management, 2(1), 66-76

Lawton, R., Conner, M., \& McEachan, R., (2009). Desire or reason: predicting health behaviors from affective and cognitive attitudes. Health Psychology, 28(1), 56-65.

Lee, J., Lee, D., Park, Y., Lee, S., \& Ha, T., (2019). Autonomous vehicles can be shared, but a feeling of ownership is important: Examination of the influential factors for intention to use autonomous vehicles. Transportation Research Part C: Emerging Technologies, 107, 411-422.

Liu, P., Yang, R., \& Xu, Z., (2019). Public acceptance of fully automated driving: Effects of social trust and risk/benefit perceptions. Risk Analysis, 39(2), 26-341.

Liljamo, T., Liimatainen, H. and Pöllänen, M., (2018). Attitudes and concerns on automated vehicles. Transportation research part F: traffic psychology and behaviour, 59, 24-44

Lim, K.B., Yeo, S.F., Goh, M.L., \& Gan, J.A.X., (2018). A study on consumer adoption of ride-hailing apps in Malaysia. Journal of Fundamental and Applied Sciences, 10(6), 1132-1142.

Lundberg, G.A. (1929). Social Research. New York Longmans. Green and Co, 168, 241-248.

Mazareanu, E. (2019). U.S. ride sharing market: Uber's user distribution by age 2017 | Statista. [online] Statista. Available at: https://www.statista.com/statistics/822833/us-ride-sharing-uber-users-age/ [Accessed 27 Nov. 2019].

McGee, P. (2021). Rolling out driverless cars is 'extraordinary grind', says Waymo boss. [online] Ft.com. Available at: $<$ https://www.ft.com/content/6b1b11ea-b50b-4dd5-802d-475c9731e89a> [Accessed 1 April 2021].

McBride, N. (2016). The ethics of driverless cars. ACM SIGCAS Computers and Society, 45(3), 179-184.

Min, S., So, K.K.F. and Jeong, M., (2019). Consumer adoption of the Uber mobile application: Insights from diffusion of innovation theory and technology acceptance model. Journal of Travel \& Tourism Marketing, 36(7), 770-783.

Muijs, D., (2010). Doing quantitative research in education with SPSS. Sage.

Nazari, F., Noruzoliaee, M. and Mohammadian, A., (2018). Shared mobility versus private car ownership: A multivariate analysis of public interest in autonomous vehicles (No. 18-04289).

Olson, J.M., \& Zanna, M.P., (1993). Attitudes and attitude change. Annual review of psychology, 44(1), 117-154.

Nuseir, M. T., Aljumah, A., \& Alshurideh, M. T. (2021). How the Business Intelligence in the New Startup Performance in UAE During COVID-19: The Mediating Role of Innovativeness. The Effect of Coronavirus Disease (COVID-19) on Business Intelligence, 334, 63-70.

Obeidat, R., Alshurideh, Z., Al Dweeri, M., \& Masa'deh, R. (2019). The influence of online revenge acts on consumers psychological and emotional states: does revenge taste sweet?. In: 33 IBIMA Conference Proceedings-Granada. Granada, Spain, 10-11.

Obeidat, U., Obeidat, B., Alrowwad, A., Alshurideh, M., Masadeh, R., \& Abuhashesh, M. (2021). The effect of intellectual capital on competitive advantage: the mediating role of innovation. Management Science Letters, 11(4), 1331-1344.

Pakusch, C., Meurer, J., Tolmie, P., \& Stevens, G., (2020). Traditional taxis vs automated taxis-Does the driver matter for Millennials?. Travel Behaviour and Society, 21, 214-225.

Panagiotopoulos, I., \& Dimitrakopoulos, G., (2018). An empirical investigation on consumers' intentions towards autonomous driving. Transportation research part C: emerging technologies, 95, 773-784.

Payre, W., Cestac, J. and Delhomme, P. (2014). Intention to use a fully automated car: Attitudes and a priori acceptability. Transportation research part F: traffic psychology and behaviour, 27, 252-263.

Peng, L., Wang, H., He, X., Guo, D., \& Lin, Y., (2014). Exploring factors affecting the user adoption of call-taxi app. ACIS.

Pettigrew, S., Talati, Z., \& Norman, R., (2018). The health benefits of autonomous vehicles: Public awareness and receptivity in Australia. Australian and New Zealand journal of public health, 42(5), 480-483.

Pettigrew, S., Worrall, C., Talati, Z., Fritschi, L., \& Norman, R., (2019). Dimensions of attitudes to autonomous vehicles. Urban, Planning and Transport Research, 7(1), 19-33.

Petty, R.E., \& Krosnick, J.A. eds., (2014). Attitude strength: Antecedents and consequences. Psychology Press.

Rathore, A. (2016). State-of-the-Art Self Driving Cars. International Journal of Conceptions on Computing and Information Technology, 4(1), 1-5.

Schoettle, B., \& Sivak, M., (2014). Public opinion about self-driving vehicles in China, India, Japan, the US, the UK, and Australia. University of Michigan, Ann Arbor, Transportation Research Institute.

Seligman, C., Kriss, M., Darley, J.M., Fazio, R.H., Becker, L.J., \& Pryor, J.B., (1979). Predicting summer energy consumption from homeowners' attitudes 1. Journal of Applied Social Psychology, 9(1), 70-90.

Semin, G., \& Fiedler, K., (1996). Applied Social Psychology. 1st ed. London: Sage.

Shariff, A., Bonnefon, J.F., \& Rahwan, I. (2017). Psychological roadblocks to the adoption of self-driving vehicles. Nature Human Behaviour, 1(10), 694-696.

Shimp, T.A., \& Kavas, A., (1984). The theory of reasoned action applied to coupon usage. Journal of Consumer Research, 11(3), 795-809.

Surden, H., \& Williams, M. (2016). Technological Opacity, Predictability, and Self-Driving Cars. SSRN Electronic Journal. 
Theodorakis, Y. (1994). Planned behavior, attitude strength, role identity, and the prediction of exercise behavior. The sport psychologist, 8(2), 149-165.

Templeton, B. (2020). Waymo And Others Resume Self-Driving Testing And Rides. [online] Forbes. Available at: $<$ https:/www.forbes.com/sites/bradtempleton/2020/05/13/waymo-and-others-resume-self-driving-testing-andrides/?sh=e6eb616515e5> [Accessed 1 April 2021].

Treiman, D.J. (2014). Quantitative data analysis: Doing social research to test ideas. John Wiley \& Sons.

Triandis, H.C. (1991). Attitude and attitude change. In the Encyclopedia of Human Biology, 1, 485-496.

Tussyadiah, I.P., Zach, F.J., \& Wang, J. (2017). Attitudes toward autonomous on demand mobility system: The case of selfdriving taxi. In Information and communication technologies in tourism 2017, 755-766. Springer, Cham.

Wang, S., Jiang, Z., Noland, R.B., \& Mondschein, A.S., (2020). Attitudes towards privately-owned and shared autonomous vehicles. Transportation research part F: traffic psychology and behaviour, 72, 297-306.

Zanna, M.P., \& Fazio, R.H., (1982). The attitude-behavior relation: Moving toward a third generation of research. In Consistency in social behavior: The Ontario symposium, 2, 283-301.

Zhu, G., So, K.K.F., \& Hudson, S., (2017). Inside the sharing economy. International Journal of Contemporary Hospitality Management, 29(9), 2218-2239.

\section{Appendix 1}

Survey Questionnaire

$\begin{array}{lc}\text { Items } & \text { Source }\end{array}$

\section{Overall Attitude}

Overall, my attitude towards self-driving vehicles is

\section{Perceived Ease-of-use}

I think using a self-driving taxi would be easy for me.

Using a ride-hailing application like Uber is straightforward.

It would be easy to book a self-driving taxi if it used the same ride-hailing application.

\section{Perceived Value}

I think there will be benefits to using self-driving taxis.

I think self-driving taxis will be useful for getting around.

I think self-driving taxis will improve my transport options.

I think I would enjoy the experience of using a self-driving taxi.

\section{Perceived Safety}

I think self-driving taxis will be safe when they are made available.

I think self-driving taxis will come with reliable safety features which have been tested thoroughly.

I would trust a self-driving taxi to get me to my destination safely.

I think self-driving taxis will be safer than regular taxis.

\section{Perceived Risk}

I think there will be a greater risk of something going wrong when using a self-driving taxi, compared to a regular taxi.

I think self-driving taxis will be vulnerable to hacking.

I think self-driving taxis will experience technical glitches whilst driving.

I think I will have to give up some digital privacy to use a self-driving taxi.

\section{Environmentalism}

Global warming is a concern for me

I would change my behaviour for environmental reasons.

I would change my preferred method of transport if there was a more environmentally friendly option.

I would pay more for a service which is more environmentally friendly.

\section{Technology}

I keep up to date with new technologies.

I knew what a self-driving car was before taking this survey.

My attitude towards technology is favourable.

I think technological advancements are beneficial to society.
(Panagiotopoulos and Dimitrakopoulos 2018)

(Fleischer and Wåhlin, 2016)

(Created for this Study)

(Kyriakidis, Happee and de Winter, 2015)

(Lee et al, 2019)

(Panagiotopoulos and Dimitrakopoulos, 2018)

(Chen, 2019)

(König and Neumayr, 2017)

(Kaur and Rampersad, 2018)

(Choi and Ji, 2015)

(König and Neumayr, 2017)

(Acheampong, and Cugurullo, 2019)

(Acheampong, and Cugurullo, 2019)

(Schoettle and Sivak, 2014)

(Schoettle and Sivak, 2014)

(Haboucha, Ishaq and Shiftan, 2017)

(Haboucha, Ishaq and Shiftan, 2017)

(Alemi et al, 2018)

(Haboucha, Ishaq and Shiftan, 2017)

(Haboucha, Ishaq and Shiftan, 2017)

(Schoettle and Sivak, 2014)

(Haboucha, Ishaq and Shiftan, 2017)

(Acheampong, and Cugurullo, 2019) 


\section{Subjective Norms}

I would use a self-driving taxi if people I respect do the same.

I would like to be seen in a self-driving taxi by my friends/ family.

I think people in my social group would like to use self-driving taxis.

(Acheampong, and Cugurullo, 2019)

(Panagiotopoulos and Dimitrakopoulos, 2018)

(Panagiotopoulos and Dimitrakopoulos, 2018)

\section{Perceived Behavioural Control}

It would be my decision whether I used a self-driving taxi or not.

(Acheampong, and Cugurullo, 2019)

If I wanted to, I would be able to afford a trip in a self-driving taxi.

(Fleischer and Wåhlin, 2016)

Intention to Use

When they are made available, I intend to use self-driving taxis.

(Panagiotopoulos and Dimitrakopoulos, 2018)

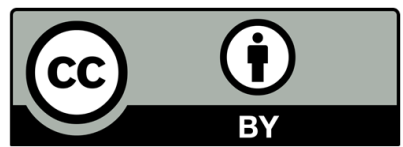

(C) 2022 by the authors; licensee Growing Science, Canada. This is an open access article distributed under the terms and conditions of the Creative Commons Attribution (CC-BY) license (http://creativecommons.org/licenses/by/4.0/). 